\title{
電氣漁網の呼究一叫. 電位分布よりみた實用型式について
}

\author{
黒机 敏 郎・巾照三千雄 \\ （鹿児葛大学水避学部） \\ Studies on the Electric Fish Screen-VII. \\ About the Practical Arrangements of Electrodes to Give \\ Proper Distribution of Potential \\ Toshiro Kurokı and Michin CHŪMAN
}

\begin{abstract}
The shapes of the electrodes which are used practically in fisheries by electric shocks are usually complicated. It is difficult to inter theoretically the distribution of the electric potential which is caused by these practical electrodes.

In this papers the anthors describe about the potential distributions which are caused hy some arrangements of model electrodes in the sea-water under the practical conditions.

Ohtaining result are as follows:

a) The difterence of the distributions between the equi-potential lines by low frequency pulse and the ones by 60 o alternative current is practically negligible (in longitude, $0.5 \%$ ).

b) The sand-bed of the sea has an effect to expand the electric potential distributions.

c) It seens more elfective to use two oppositely cluarged electrodes at the sides of the mouth of the trawl-net than to use one electrode at the lower-side of the mouth and another at the ship-side.

d) The potentical distribution showed in the suctorial electric fishing method which was tested ha F. CERnIGIN shonld be effective.

\section{I. 緒}

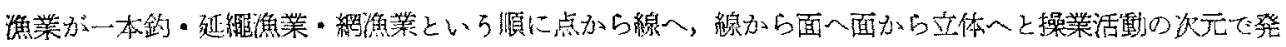

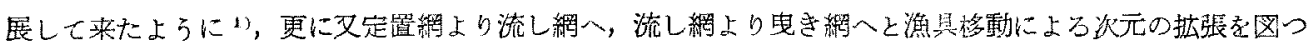

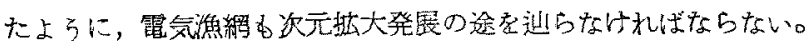

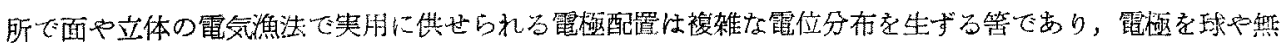

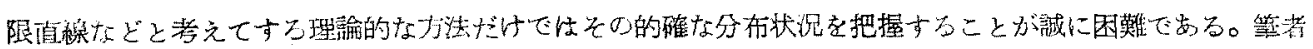

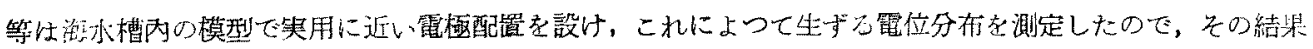
家こつに報告する。
\end{abstract}

\section{II. 実験の方法}

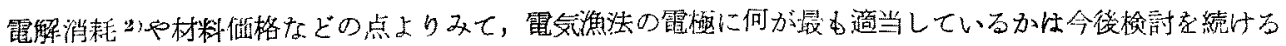

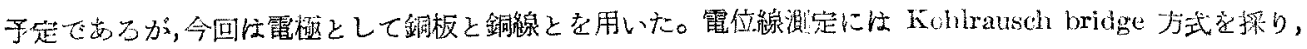

1951 年 9 月 25 日受理 
382

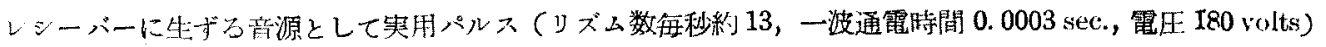

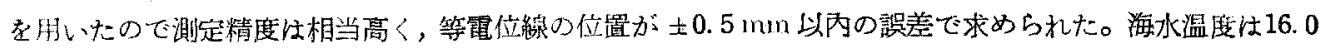

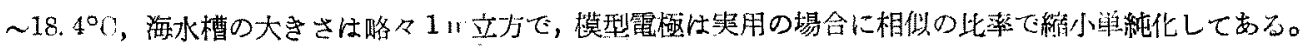

\section{目. 実験極果並に考察}

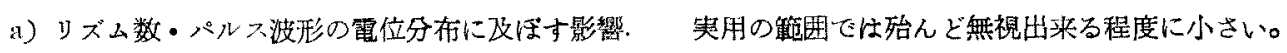

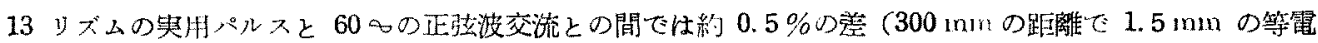

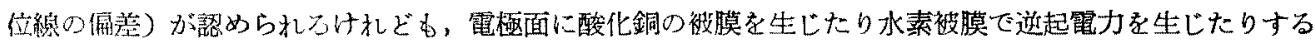

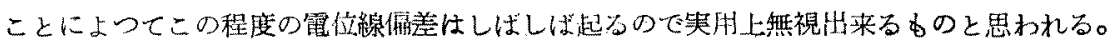

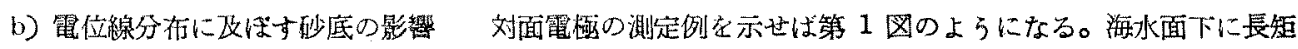

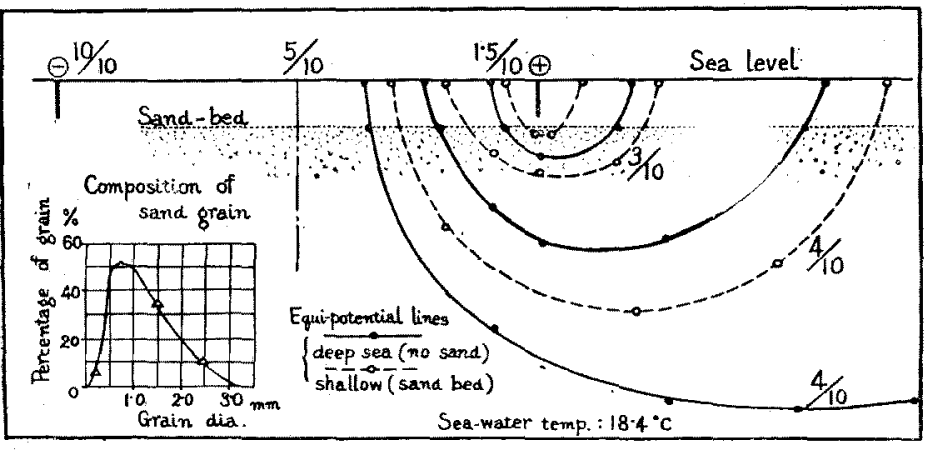
形の溥い面電㥛を鎑淔に置 いた洔電㥛面の中心で面に 垂直な方向で等電位缐を求 めると，哚、場合垁線の如 くなる電位尔有が浅底砂面 のむる場合には破線の上う に坛がつて来る。両極の中 央に $5 / 10$ の等電位線が鋁 面に生ずることは耑場合に つて同じでありこの左 右に同様な刘称形の等笔位

Fig. 1. Effect of the sand-bed to equi-potential line. 線分布が現われるので片側でサる图に示した。

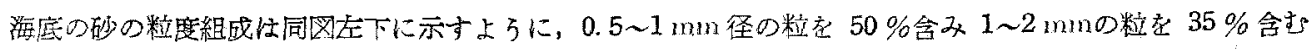

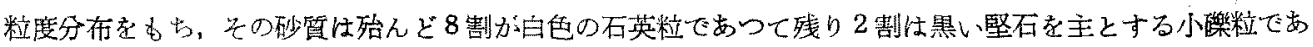

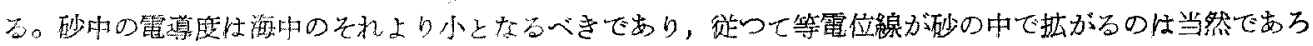
ろ。浅、場合海水中の電位分布む砂底のために引竞ずられて拡がつたるのと考えられる。この結果より推せ ば岩谯地带の追い出しについて社電力的に相当有利な点を期待し得上ら。

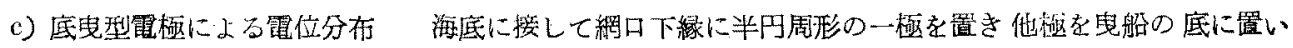

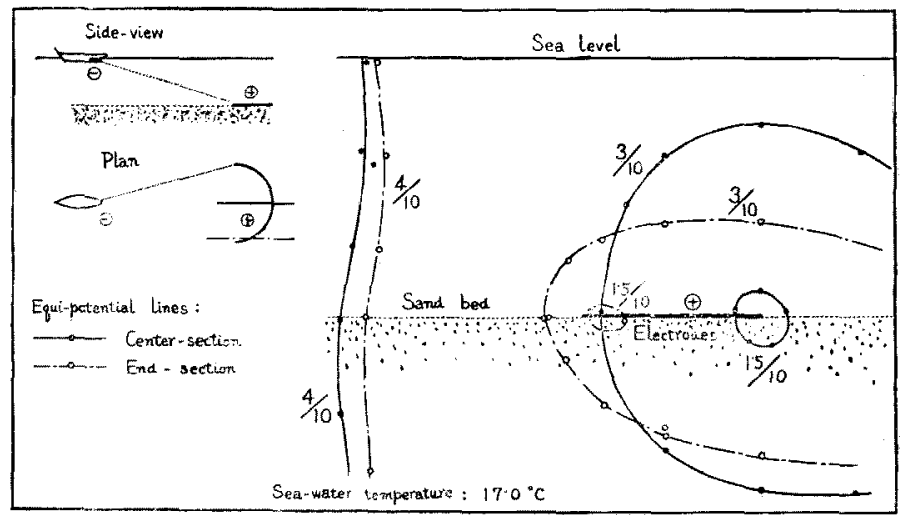

Fig. 2. Arrangement of electrodes; one aft, another at the lower-side of the mouth of net. 


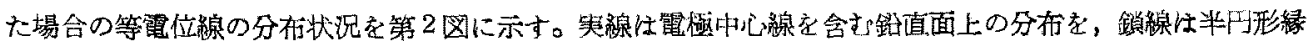
端て同面に平行な鉛直面上の分布をあらわす。見る通り $3 / 10$ とか $4 / 10$ とかの等電位線が相当执がつて前

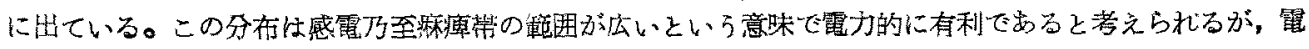

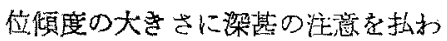
字ければ絧口前で魚群至扈い散らす

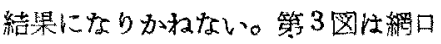
の上縁下緑に等しい半円周猪の二極 を置いた例であ。前図と同じく実 線柱中心断面での，鎖線住縁端に括 ける平行直面での，電位分布状现を それぞれ示す。このやり方で前の 場合と比へて等霹位線分布が相当狭 められている。これ经前例より筆力 的に柱不利で出らけれどす央用上次

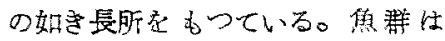
6.5/10 位の等電位線にほ济平行に 絧口へ近づくから追い执、效果考受

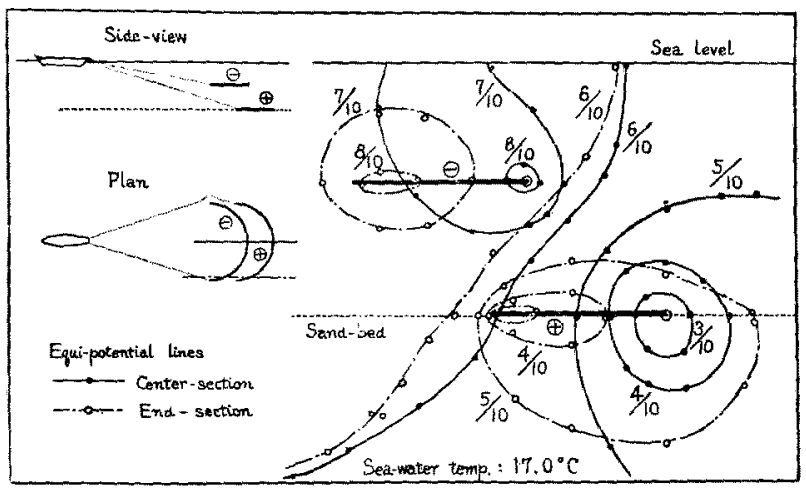

Fig. 3. Arrangenent of two electrodes; at the upper-side and the lower-side of the mouth of net.

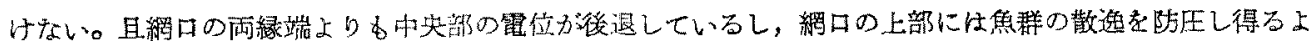

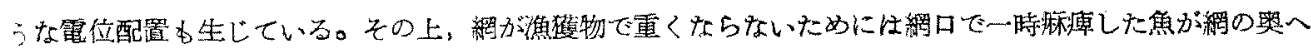

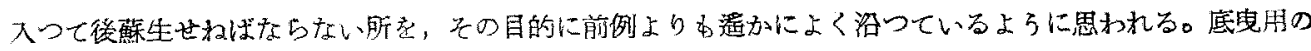

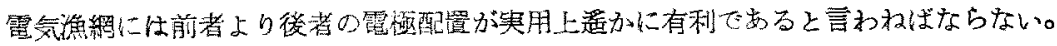

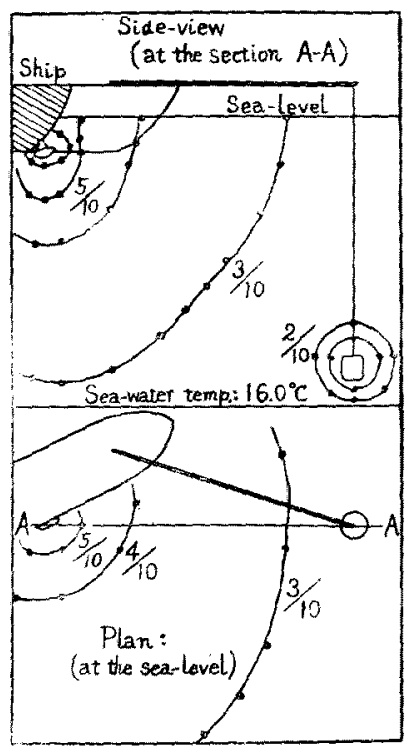

Fig. 4. Arrangement of wo pecial electrodes; at sucturia ? vectric fishing.

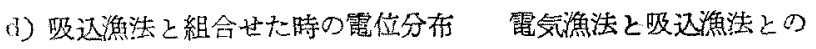

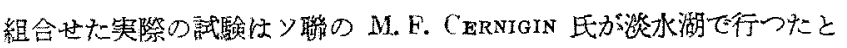

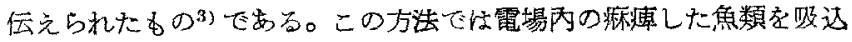

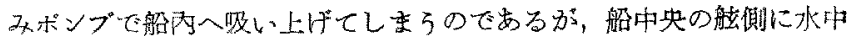

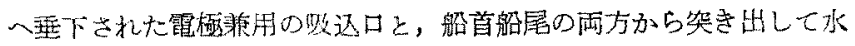

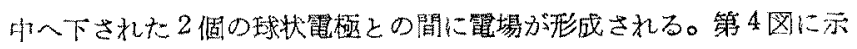

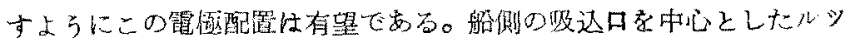

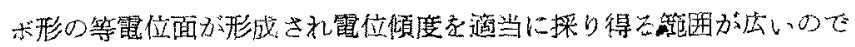

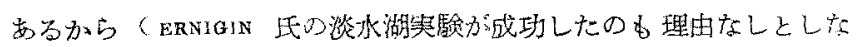

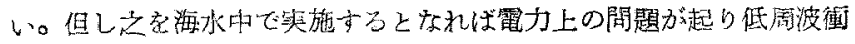

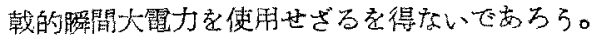

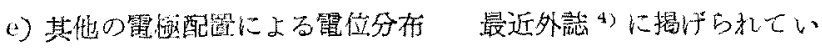

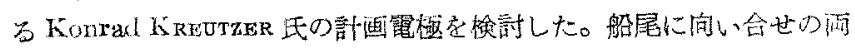

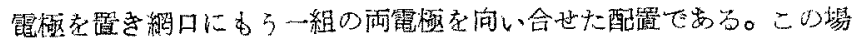

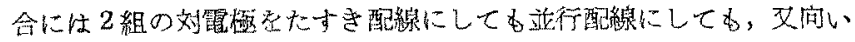

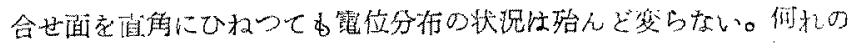

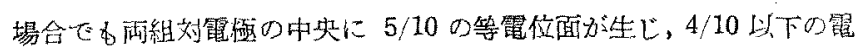

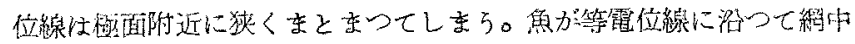

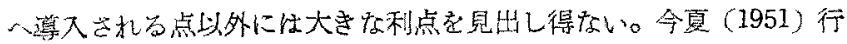

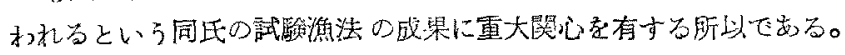

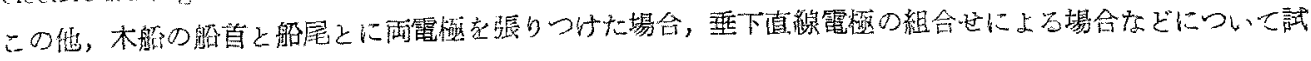


384

験したが特異な点を見出さなかつたので，本報にはこれらを省略する。

\section{N. 結聇}

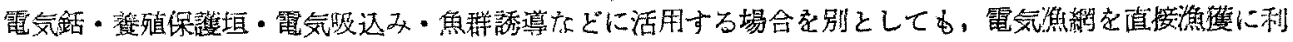

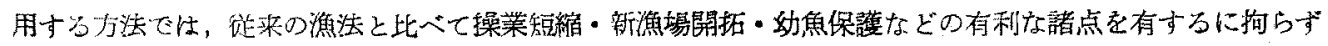

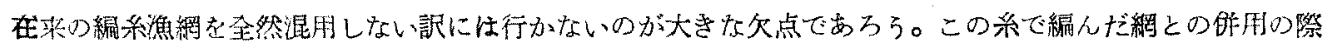

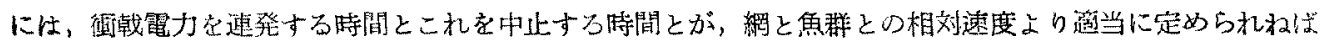

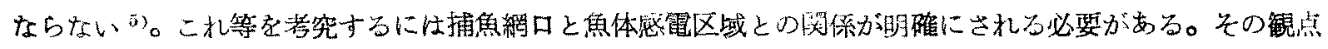

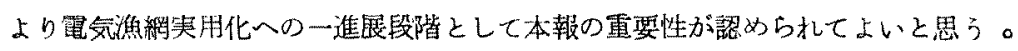

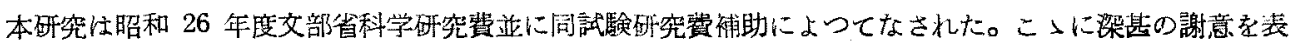
ナる次第である。

女献

1) 黑木：日本機㣝学会誌，53(383), 1950

2) 墅木：機械の研究，3 (7) 1951

3) Commercial Fisheries Abstracts, 3 (12), 1950 [Commercial Fisheries Review, 12 (7) 1950]

4) Commercial Fitheries Review, 13 (1), 1951

5) 黒木：日本水造学会誌，末罃表 